\title{
Consorciação e manejo de Brachiaria decumbens em mudas de cafeeiros infestados com Pratylenchus brachyurus em condições de casa de vegetação
}

\author{
Intercropping and management of Brachiaria decumbens in coffee seedlings \\ infested with Pratylenchus brachyurus under greenhouse conditions
}

\author{
Roberto Kazuhiro Kubo ${ }^{I^{*}}$ Juliana Eulalio ${ }^{\mathrm{I}}$ \\ Claudio Marcelo Gonçalves de Oliveira ${ }^{\mathrm{I}}$
}

RESUMO

Com o objetivo de avaliar o efeito da consorciação e manejo de Brachiaria decumbens cv. 'Basilisk' em cafeeiro (Coffea arabica cv. 'Catuai Vermelho') infestado por Pratylenchus brachyurus $(\mathrm{Pb})$, o presente experimento foi desenvolvido em condições de casa de vegetação. Os tratamentos utilizados, com cinco repetições, foram: 1. Café não inoculado no limpo; 2. Café não inoculado consorciado com $\boldsymbol{B}$. decumbens; 3. Café inoculado com 5000 juvenis e adultos de Pb por vaso (10L), no limpo; 4. Café inoculado com $\mathrm{Pb}$ consorciado com B. decumbens podadas semanalmente; 5. Café inoculado com Pb consorciado com $\boldsymbol{B}$. decumbens com aplicação do herbicida glifosato. Aos 3, 4, 7, 10 e 11 meses após transplante dos cafeeiros, houve um aumento significativo na altura das plantas de cafeeiro sem nematoide mantidas no limpo, comparadas com os tratamentos com cafeeiros em solo infestado com $\mathrm{Pb}$ consorciado com $\boldsymbol{B}$. decumbens podadas e café em solo infestado com $\mathrm{Pb}$ consorciado com $\boldsymbol{B}$. decumbens com aplicação de glifosato. Na avaliação final, realizada 278 dias após à inoculação das plantas, o peso da matéria seca da parte aérea nos tratamentos com $\mathrm{Pb}$ consorciado com braquiária e com aplicação de glifosato apresentaram menores valores, quando comparado com a testemunha sem nematoide e sem plantas consorciadas. Com relação ao peso da matéria fresca das raizes, todos os tratamentos foram significativamente mais baixos do que a testemunha sem nematoide e sem consorciação. A população final de $\boldsymbol{P}$. brachyurus nas raizes foi maior quando o café foi consorciado com braquiária.

Palavras-chave: nematoides das lesões, Coffea arabica, cobertura vegetal, densidades populacionais.

\section{ABSTRACT}

The objective of this study was to evaluate the effect of intercropping and management of Brachiaria decumbens $c v$. 'Basilisk' in coffee (Coffea arabica cv. 'Catuai vermelho') infested with Pratylenchus brachyurus $(\mathrm{Pb})$, under greenhouse conditions.
The treatments with five replicates were: 1 . Coffee without $\mathrm{Pb} ; 2$. Coffee without $\mathrm{Pb}$ and intercropped with $\boldsymbol{B}$. decumbens; 3. Coffee inoculated with 5000 juveniles and adults Pb per pot (10L) kept in clean; 4. Coffee inoculated with Pb intercropped with $\boldsymbol{B}$. decumbens pruned weekly; 5. Coffee inoculated with Pb intercropped with $\boldsymbol{B}$. decumbens with application of the herbicide glyphosate. At 3, 4, 7, 10 and 11 months after transplantation of coffee plants, there was a significant increase in the height of coffee plants without nematode kept in clean, compared with treatments with coffee in infested soil with Pb intercropped with $\boldsymbol{B}$. decumbens pruned and coffee in soil infested with Pb intercropped with B. decumbens with application of glyphosate. In the final evaluation, 278 days after inoculation, the dry weight of shoots in treatments with $\mathrm{Pb}$ and brachiaria and application of glyphosate were significantly lower when compared with untreated plants without nematode and intercropping. The weight of fresh roots, was significantly lower in all treatments compared to the control untreated plot. and without intercropping. The final population of $\boldsymbol{P}$. brachyurus in roots was greater when coffee was intercropped with $\boldsymbol{B}$. decumbens.

Key words: Lesion-nematode, Coffea arabica, cover crop, population densities.

\section{INTRODUÇÃO}

Após amplo levantamento em cafezais do estado de São Paulo, determinou-se a importância e a ocorrência dos nematoides das lesões. A espécie de Pratylenchus mais frequente foi $\boldsymbol{P}$. brachyurus, ocorrendo em 18,3\% das raízes, mas geralmente em baixas densidades. Danos foram observados em cafezais jovens, implantados em áreas anteriormente de pastagens, com gramíneas utilizadas como cobertura vegetal. Uma população significativamente maior de espécimes de $\boldsymbol{P}$. brachyurus foi encontrada

\footnotetext{
ILaboratório de Nematologia, Instituto Biologico, CP 70, 13001-970, Campinas, SP, Brasil. E-mail: kubo@biologico.sp.gov.br. *Autor para correspondência.
} 
nas raízes de Brachiaria em relação às raízes de cafeeiros (KUBO et al., 2000; KUBO et al., 2004). Trabalhos anteriores relataram que $\boldsymbol{P}$. brachyurus é a espécie de Pratylenchus mais disseminada em cafezais do estado de São Paulo (LORDELLO et al., 1968; GONÇALVES et al., 1978) e sul do estado de Minas Gerais (D’ANTONIO et al., 1980).

$$
\text { Segundo LORDELLO (1972), }
$$

$\boldsymbol{P}$ brachyurus e $\boldsymbol{P}$. coffeae prejudicam o desenvolvimento do cafeeiro, que, quando infestado, exibe raízes pequenas e, na parte aérea, desfolhamento e fortes sintomas de deficiências nutricionais. Ainda de acordo com o autor, as duas espécies são polífagas e, no caso de $\boldsymbol{P}$. brachyurus, por se multiplicar em diversas gramíneas, causa preocupação nos cafezais instalados em terrenos antes ocupados por pastagens. GONÇALVES (1995) observou que, em solos arenosos, cafeeiros infestados por P. brachyurus apresentavam desenvolvimento insatisfatório e raízes reduzidas. INOMOTO et al. (1998) conduziram um experimento em casa de vegetação, utilizando-se plântulas de cafeeiro cvs. 'Mundo Novo' e 'Catuaí'. As avaliações comprovaram que $\boldsymbol{P}$. brachyurus influenciou negativamente o crescimento das plantas. Entretanto, o nematoide não se multiplicou nas duas cultivares (o fator de reprodução foi menor que um), o que caracterizaria o cafeeiro como intolerante a $\boldsymbol{P}$. brachyurus, segundo o conceito de DROPKIN \& NELSON (1960). Esse fato foi confirmado posteriormente por OLIVEIRA et al. (1999), ao estudarem o efeito de diferentes níveis populacionais de $\boldsymbol{P}$. brachyurus no crescimento de plântulas de Coffea arabica, cv. 'Mundo Novo' e de C. canephora $\mathrm{cv}$. 'Apoatã', em condições de casa de vegetação. Os autores concluíram que ambas as espécies de cafeeiros foram prejudicadas desde os mais baixos níveis populacionais e se comportaram como intolerantes a $\boldsymbol{P}$. brachyurus.

Como o cafeeiro é hospedeiro desfavorável a $\boldsymbol{P}$. brachyurus, provavelmente as ervas daninhas ou coberturas presentes na entrelinha do cafezal sejam as principais responsáveis pela manutenção de altas populações do nematoide na cultura do café. Entretanto, os relatos anteriormente mencionados referem-se apenas às observações de campo sobre os danos em cafeeiros implantados em áreas de pastagens e que esses sintomas de danos atribuídos aos nematoides poderiam também estar associados a outros microorganismos oportunistas e pragas. Portanto, tais relatos carecem de comprovação científica em condições controladas. Assim, especula-se que o uso de Brachiaria decumbens em consorciação possibilitará elevada multiplicação dos nematoides das lesões e o manejo dessas plantas tenha importância no controle de $\boldsymbol{P}$. brachyurus no cafeeiro.

Dessa forma, o presente estudo foi desenvolvido em condições de casa de vegetação com o objetivo de avaliar a influência da consorciação e manejo químico e cultural de B. decumbens, cv. 'Basilisk', em cafeeiro (Coffea arabica cv. 'Catuaí Vermelho'), nas densidades populacionais de $\boldsymbol{P}$. brachyurus, nas raízes dos cafeeiros e da gramínea. Verificou-se o efeito da consorciação de B. decumbens podada, simulando o roçamento em cafezais, permitindo a multiplicação dos nematoides nas raízes da gramínea. Comparou-se esse tratamento com a capina manual, incorporando-se as raízes da brachiaria e a aplicação do herbicida sistêmico (glifosato) somente na parte aérea da gramínea e o efeito dos referidos tratamentos sobre a densidade populacional e danos de $\boldsymbol{P}$. brachyurus às raízes e ao desenvolvimento da parte aérea do cafeeiro. Partiu-se da hipótese que, por ser uma espécie de nematoide migratória, provavelmente os nematoides presentes nas raízes das gramíneas migrariam para as raízes do café, causando danos.

\section{MATERIAL E MÉTODOS}

A população pura de $\boldsymbol{P}$. brachyurus foi isolada de raízes de cafeeiro proveniente de Dracena, SP, e a sua multiplicação foi feita em plantas de milho, cultivar 'AG 8060', cultivadas em vasos de 10 litros de capacidade, contendo solo esterilizado em autoclave.

No presente experimento, utilizaram-se vasos de 10L, contendo solo previamente autoclavado a $120^{\circ} \mathrm{C}$ por duas horas. A seguir, realizou-se a semeadura de $2 \mathrm{~g}$ de sementes de B. decumbens cv. 'Basilisk' distribuída homogeneamente em círculo a cerca de $2 \mathrm{~cm}$ das bordas de cada vaso, visando a permitir o posterior plantio de mudas de cafeeiro no centro deste.

Utilizou-se o delineamento inteiramente casualizado, com cinco repetições e cinco tratamentos. Os tratamentos utilizados foram: 1-Testemunha, café não inoculado com $\boldsymbol{P}$. brachyurus e mantido no limpo; 2-Café não inoculado e consorciado $\operatorname{com} \boldsymbol{B}$. decumbens $\mathrm{cv}$. 'Basilisk', semanalmente podadas; 3-Café inoculado com $\boldsymbol{P}$. brachyurus, mantido no limpo; 4-Café inoculado com $\boldsymbol{P}$. brachyurus e consorciado com B. decumbens, semanalmente podadas; 5-Café inoculado com $\boldsymbol{P}$. brachyurus e consorciado com $\boldsymbol{B}$. decumbens, com aplicação do herbicida sistêmico glifosato.

Para a obtenção do inóculo, realizou-se a extração de juvenis e adultos de $\boldsymbol{P}$. brachyurus a partir de população pura. Para isso, as raízes de milho 
AG 8060 infestadas foram separadas do solo, lavadas, cortadas em pedaços de $0,5 \mathrm{~cm}$ e processadas pelo método da trituração, peneiramento e centrifugação de COOLEN \& D’HERDE (1972). A contagem foi feita em lâmina de Peters $(1 \mathrm{ml})$, com volume igual a um décimo da suspensão. A inoculação do experimento foi feita aos 22 dias após a semeadura da braquiária com 5000 espécimes de $\boldsymbol{P}$. brachyurus, (juvenis e adultos) por vaso, depositados uniformemente em orifícios próximos às raízes da gramínea, exceto a testemunha não inoculada.

Aos 20 dias após à inoculação das plântulas de B. decumbens, mudas de café Coffea arabica cv. 'Catuaí Vermelho' com cinco pares de folhas verdadeiras foram transplantadas no centro dos vasos com seus respectivos tratamentos. Nos tratamentos 1 e 3 , que foram mantidos no limpo, as plantas de braquiária foram arrancadas; as suas raízes foram incorporadas e as partes aéreas cortadas em pequenos pedaços e mantidas na superfície do solo do seu respectivo vaso. No tratamento 5, as plantas de braquiária receberam tratamento com o herbicida sistêmico glifosato em local isolado na dosagem recomendada. As partes aéreas foram cuidadosamente acomodadas nas bordas de cada vaso e deixadas para secar naturalmente ao redor das plantas de café, formando cobertura morta. Ressalte-se que as mudas de café somente foram transplantadas após a completa absorção e secamento do glifosato nas folhas da braquiária e que elas não entraram em contato com a parte aérea dos cafeeiros. Além disso, a parte aérea da braquiária foi cuidadosamente acamada e disposta na borda de cada vaso, deixando livre a área central para o plantio da muda de cafeeiro. Nos tratamentos 2 e 4, as plantas de braquiária foram podadas a uma altura de cerca de $5 \mathrm{~cm}$ e a parte aérea foi deixada ao redor de cada planta como cobertura morta.

$\mathrm{O}$ experimento foi mantido em casa de vegetação em condições controladas. As plantas receberam irrigação manual, tratamento fitossanitário e adubações de acordo com suas necessidades, utilizando-se as mesmas dosagens em todos os tratamentos. As plantas de braquiária foram podadas semanalmente com o auxílio de uma tesoura, visando a evitar o sombreamento e a competição por luz com as plantas de café. A altura das plantas de café foi mensurada aos $3,4,7,10$ e 11 meses após o plantio das mudas de cafeeiros.

A avaliação final foi realizada 278 dias após a inoculação das plantas. Após a avaliação da altura, a parte aérea de cada planta de café foi seccionada na altura do colo e colocada em envelope perfurado, identificado de acordo com o respectivo tratamento e levado em estufa de secagem para obtenção do peso da matéria seca da parte aérea. $O$ sistema radicular foi retirado dos recipientes juntamente com o solo e as suas raízes foram cuidadosamente lavadas em água corrente. As raízes foram previamente secas, retirando-se o excesso de umidade com papel toalha, para obtenção do peso da matéria fresca do sistema radicular.

A população final do nematoide foi estimada em cinco repetições de cada tratamento, pela contagem dos nematoides extraídos das raízes de café e braquiária pelo método de peneiramento e centrifugação de COOLEN \& D'HERDE (1972). A contagem foi feita em lâmina de Peters $(1 \mathrm{ml})$, igual a um décimo da suspensão. $\mathrm{O}$ valor final apresentado é igual a contagem x 10. Através da densidade populacional obtida através da contagem da alíquota de $10 \mathrm{~g}$, foi estimada a população total na raiz.

Os dados da altura das plantas, peso da massa seca da parte aérea e peso da massa fresca do sistema radicular foram analisados usando um programa Sasm-Agri (CANTIERI et al, 2001) para análise estatística, comparando-os pelo Teste de Tukey a 5\% de significância.

\section{RESULTADOS E DISCUSSÃO}

Diferenças no desenvolvimento da parte aérea das plantas foram observadas aos 3, 4, 7, 10 e 11 meses após o plantio dos cafeeiros $\boldsymbol{C}$. arabica, cv. 'Catuaí Vermelho' nos diferentes tratamentos. Nessas épocas de avaliação, observou-se que houve um aumento significativo na altura das plantas de cafeeiro sem nematoide, mantidas no limpo, comparadas com os tratamentos com cafeeiros em solo infestado com P. brachyurus, consorciado com gramíneas podadas e café em solo infestado com $\boldsymbol{P}$. brachyurus, consorciado com $\boldsymbol{B}$. decumbens, com aplicação do herbicida sistêmico glifosato.

O tratamento de café em solo infestado com $\boldsymbol{P}$. brachyurus sem plantas consorciadas não diferiu significativamente em relação à altura da testemunha. $\mathrm{O}$ tratamento com café não inoculado, consorciado com B. decumbens cv. 'Basilisk' diferiu significativamente do café não inoculado no limpo aos 10 e 11 meses após o plantio, evidenciando que houve uma competição por nutrientes com o desenvolvimento pleno da gramínea em detrimento ao crescimento dos cafeeiros. Tal fato foi comprovado por DIAS et al. (2004), que constataram uma supressão de crescimento de cafeeiros submetidos a diferentes densidades de transplante da braquiária. Observou-se também que a menor média da altura aos 3 meses após o plantio foi obtida no tratamento 
com café inoculado com $\boldsymbol{P}$. brachyurus consorciado com $\boldsymbol{B}$. decumbens, com aplicação do herbicida (Tabela 1). Provavelmente, após a aplicação do glifosato e consequente definhamento e morte gradual da gramínea, os espécimes de $\boldsymbol{P}$. brachyurus que infestavam as raízes da braquiária migraram para as raízes de café, causando danos e reduzindo o desenvolvimento da planta. Também observou-se que as plantas de café do referido tratamento mostravamse com sintomas de amarelecimento mais evidentes e um menor desenvolvimento em relação aos outros tratamentos. No entanto, essa tendência de causar severos danos não persistiu e, após 4 meses do plantio, houve recuperação da planta. Isso provavelmente se deve à baixa capacidade reprodutiva de $\boldsymbol{P}$. brachyurus em cafeeiros (INOMOTO et al., 1998; OLIVEIRA et al., 1999) que não se mantiveram em altas densidades populacionais exclusivamente com raízes de café e as populações remanescentes não foram capazes de causar danos significativos às raízes de cafeeiros, em plantas com mais de 6 pares de folhas verdadeiras. Os menores valores da altura foram constatados no tratamento com café inoculado com $\boldsymbol{P}$. brachyurus consorciado com B. decumbens podadas. Isso se deve, provavelmente, ao contínuo fornecimento de inóculo de $\boldsymbol{P}$. brachyurus que se multiplicaram nas raízes da braquiária, migraram e atacaram as raízes do café, causando danos severos. Somente a consorciação com braquiária, sem a presença de $\boldsymbol{P}$. brachyurus, prejudicou o desenvolvimento do cafeeiro, devido à competição por nutrientes, resultado que já fora constatado por DIAS et al. (2004). No entanto, os danos às raízes e no desenvolvimento dos cafeeiros foram significativamente agravados quando associados à presença do nematoide, comparada à ação isolada da competição por braquiária.

Os resultados obtidos do peso da matéria fresca do sistema radicular e do peso da matéria seca da parte aérea podem ser visualizados na tabela 2. Observouse que os cafeeiros não inoculados mantidos no limpo tiveram peso da massa fresca das raízes significativamente maior que os demais tratamentos. A ação de $\boldsymbol{P}$. brachyurus reduziu significativamente as raízes das plantas em todos os tratamentos inoculados com esse nematoide, mas o tratamento com café inoculado com $\boldsymbol{P}$. brachyurus consorciado com $\boldsymbol{B}$. decumbens podadas foi significativamente menor, quando comparado com os demais tratamentos. Além disso, somente nesse tratamento consorciado com braquiária, foram observadas necroses mais acentuadas com muitas raízes escurecidas e uma maior população final de $\boldsymbol{P}$. brachyurus (Tabela 2, Figura 1). Esses resultados são concordantes com aqueles obtidos por OLIVEIRA et al. (1999), em que não observaram necroses nas raízes dos cafeeiros avaliados, exceto quanto a plantas de $\boldsymbol{C}$. arabica cv. 'Mundo Novo', que foram inoculadas com $9000 \mathrm{ou}$ 27000 nematoides/ plântula.

Com relação ao peso da massa seca da parte aérea (PMSPA), o café não inoculado no limpo diferiu dos demais tratamentos, exceto no tratamento com café inoculado com $\boldsymbol{P}$. brachyurus e mantido no limpo, livre de plantas invasoras. Os cafeeiros não são bons multiplicadores de $\boldsymbol{P}$. brachyurus (INOMOTO et al., 1998 e OLIVEIRA et al.,1999) e a densidade populacional inicial inoculada não causou danos à parte aérea dos cafeeiros aos 278 dias após à inoculação das plantas. Provavelmente, as raízes inoculadas arrancadas e incorporadas da braquiária tornam-se rapidamente impróprias para a permanência desses nematoides nas raízes em decomposição. O menor valor do PMSPA foi encontrado para o tratamento com café inoculado com $\boldsymbol{P}$. brachyurus, consorciado com $\boldsymbol{B}$. decumbens podadas. As raízes dessa gramínea favorecem a intensa multiplicação desse nematoide e parte dessa

Tabela 1 - Altura dos cafeeiros aos 3, 4, 7, 10 e 11 meses após o plantio, submetidos a diferentes tratamentos.

\begin{tabular}{|c|c|c|c|c|c|}
\hline \multirow{2}{*}{ Tratamentos } & \multicolumn{5}{|c|}{----------- Altura das plantas $(\mathrm{cm})$ após plantio ----------- } \\
\hline & 3 meses & 4 meses & 7 meses & 10 meses & 11 meses \\
\hline 1. Café não inoculado, no limpo & $20,4 \mathrm{a}$ & $27,5 \mathrm{a}$ & $38,2 \mathrm{a}$ & $51,3 \mathrm{a}$ & $53 \mathrm{a}$ \\
\hline 2. Café não inoculado e consorciado com Brachiaria decumbens cv. 'Basilisk' & $17,1 \mathrm{ab}$ & $21,1 \mathrm{ab}$ & $32,6 \mathrm{ab}$ & $42,1 \mathrm{~b}$ & $43,1 \mathrm{~b}$ \\
\hline 3. Café inoculado com $\boldsymbol{P}$. brachyurus, no limpo & $15,8 \mathrm{ab}$ & $21,3 \mathrm{ab}$ & $32,6 \mathrm{ab}$ & $45,9 \mathrm{ab}$ & $47,3 \mathrm{ab}$ \\
\hline 4. Café inoculado com $\boldsymbol{P}$. brachyurus e consorciado com $\boldsymbol{B}$. decumbens podadas & $13,9 \mathrm{~b}$ & $17,2 \mathrm{~b}$ & $25,1 \mathrm{~b}$ & $33,1 \mathrm{c}$ & $34,5 \mathrm{c}$ \\
\hline $\begin{array}{l}\text { 5. Café inoculado com } \boldsymbol{P} \text {. brachyurus e consorciado com } \boldsymbol{B} \text {. decumbens com } \\
\text { aplicação do herbicida sistêmico glifosato }\end{array}$ & $12,2 \mathrm{~b}$ & $16,8 \mathrm{~b}$ & $28,5 \mathrm{~b}$ & $40,6 \mathrm{~b}$ & $42,2 \mathrm{~b}$ \\
\hline
\end{tabular}

Valores são médias de cinco repetições; valores seguidos de mesma letra na coluna não diferem segundo o teste de Tukey a 5\% de significância.

Ciência Rural, v.45, n.11, nov, 2015. 
Tabela 2 - Efeito do manejo de Brachiaria decumbens em plantas infestadas por Pratylenchus brachyurus no crescimento de cafeeiro, cv. 'Catuaí Vermelho', pela medição do peso da massa seca da parte aérea (PMSPA), do peso da massa fresca das raízes (PMFR), população final dos nematoides (Pf), fator de multiplicação dos nematoides (Pf/Pi) e população final dos nematoides na braquiária (Pf brach), aos 278 dias após a inoculação das plantas. *A população final no solo (S) foi muito baixa (praticamente nula) em todos os tratamentos.

\begin{tabular}{|c|c|c|c|c|c|}
\hline \multirow{2}{*}{ Tratamentos } & \multicolumn{5}{|c|}{ 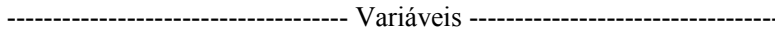 } \\
\hline & PMSPA (g) & $\operatorname{PMFR}(\mathrm{g})$ & $\mathrm{Pf}$ & $\mathrm{Pf} / \mathrm{Pi}$ & Pf brach \\
\hline 1. Café não inoculado, no limpo & 35,9 a & $219,0 \mathrm{a}$ & 0 & & \\
\hline $\begin{array}{l}\text { 2. Café não inoculado e consorciado com Brachiaria decumbens } \\
\text { cv. 'Basilisk' }\end{array}$ & $18,8 \mathrm{~cd}$ & $100,8 \mathrm{~b}$ & 0 & & \\
\hline 3. Café inoculado com $\boldsymbol{P}$. brachyurus, no limpo & $28,5 \mathrm{ab}$ & $128,7 \mathrm{~b}$ & $2704,4 \mathrm{~S}=0 *$ & 0,54 & \\
\hline $\begin{array}{l}\text { 4. Café inoculado com } \boldsymbol{P} \text {. brachyurus e consorciado com } \boldsymbol{B} \text {. } \\
\text { decumbens podadas }\end{array}$ & $12,2 \mathrm{~d}$ & $47,6 \mathrm{c}$ & $4679,4 \mathrm{~S}=0 *$ & 0,94 & 3733,4 \\
\hline $\begin{array}{l}\text { 5. Café inoculado com } \boldsymbol{P} \text {. brachyurus e consorciado com } \boldsymbol{B} \text {. } \\
\text { decumbens com aplicação do herbicida sistêmico }\end{array}$ & $24,3 \mathrm{bc}$ & $119,8 \mathrm{~b}$ & $910,7 \mathrm{~S}=0 *$ & 0,18 & \\
\hline
\end{tabular}

Valores são médias de cinco repetições; valores seguidos de mesma letra na coluna não diferem segundo o teste de Tukey a $5 \%$ de significância.

população migrou, causando danos às raízes do café e resultando em menor crescimento da parte aérea do cafeeiro. (Tabela 2, Figura 1).

De acordo com INOMOTO et al. (1998) e OLIVEIRA et al. (1999), o cafeeiro é intolerante ao ataque desse nematoide, assim, os dados do presente trabalho comprovam a importância das plantas consorciadas nos danos causados por $\boldsymbol{P}$. brachyurus em cafeeiros e explicam os prejuízos observados em condições de campo por LORDELLO (1972) e KUBO et al. $(2000 ; 2004)$ em cafezais implantados em áreas de pastagens. No entanto, em condições de campo, os danos podem ter sido agravados pela ação conjunta de microorganismos oportunistas, favorecidos pela abertura de porta de entrada através dos orifícios e lesões provocados pelos nematoides. Por esse motivo, tais constatações careciam de comprovação científica através de experimentos conduzidos em solo esterilizado e condições controladas.

Devido à baixa capacidade reprodutiva de $\boldsymbol{P}$. brachyurus em cafeeiros (INOMOTO et al., 1998; OLIVEIRA et al., 1999) e a sua intolerância à presença desses nematoides, mesmo em baixos níveis populacionais (OLIVEIRA et al., 1999), a planta consorciada nas entrelinhas dos cafezais torna-se de fundamental importância, uma vez que plantas favoráveis à multiplicação de $\boldsymbol{P}$. brachyurus possibilitarão um significativo aumento populacional, ocasionando o agravamento dos danos causados por esses nematoides. Os resultados concordam com os relatos de LORDELLO (1972) que $\boldsymbol{P}$. brachyurus é uma espécie polífaga, multiplicando-se em diversas gramíneas e causando preocupação nos cafezais instalados em terrenos antes ocupados por pastagens.
A principal hipótese é que, com a elevação da densidade populacional de $\boldsymbol{P}$. brachyurus nas raízes da braquiária, parte dessa população migre, elevando o nível populacional desse nematoide nas raízes de café. O tratamento do café não inoculado, consorciado com B. decumbens cv. 'Basilisk', teve o seu crescimento significativamente reduzido, quando comparado com o tratamento de café não inoculado mantido no limpo, indicando que a simples presença dessa gramínea interferiu no desenvolvimento do café, sendo tal fato comprovado por DIAS et al. (2004). O oposto ocorreu com cafeeiro inoculado e mantido no limpo, que não diferiu estatisticamente do cafeeiro não inoculado e mantido no limpo (Tabela 2, Figura 1). A população final média nas raízes de braquiária foi de 3733,4 espécimes de $\boldsymbol{P}$. brachyurus obtidas em raízes com peso médio da massa fresca das raízes de 14,1g. Convém frisar que o peso médio da massa fresca das raízes de café foi de, no mínimo, 47,6g, atingindo até $128,67 \mathrm{~g}$ nos cafeeiros inoculados (Tabela 2). Portanto, a população média final por grama de raiz foi significativamente maior na braquiária, comparada com a população média final por grama de raiz de café em todos os tratamentos que foram inoculados com $\boldsymbol{P}$. brachyurus. Isso demonstra a altíssima capacidade reprodutiva desse nematoide em raízes de braquiária, possibilitando o fornecimento contínuo de espécimes de $\boldsymbol{P}$. brachyurus que parasitam as raízes de café.

Em plantações de café, P. brachyurus pode sobreviver em plantas daninhas, restos culturais de cultivos anteriores ou plantas cultivadas nas entrelinhas. STRADIOTO et al. (1983) relataram que, após a colheita de milho, espécimes de $\boldsymbol{P}$. 

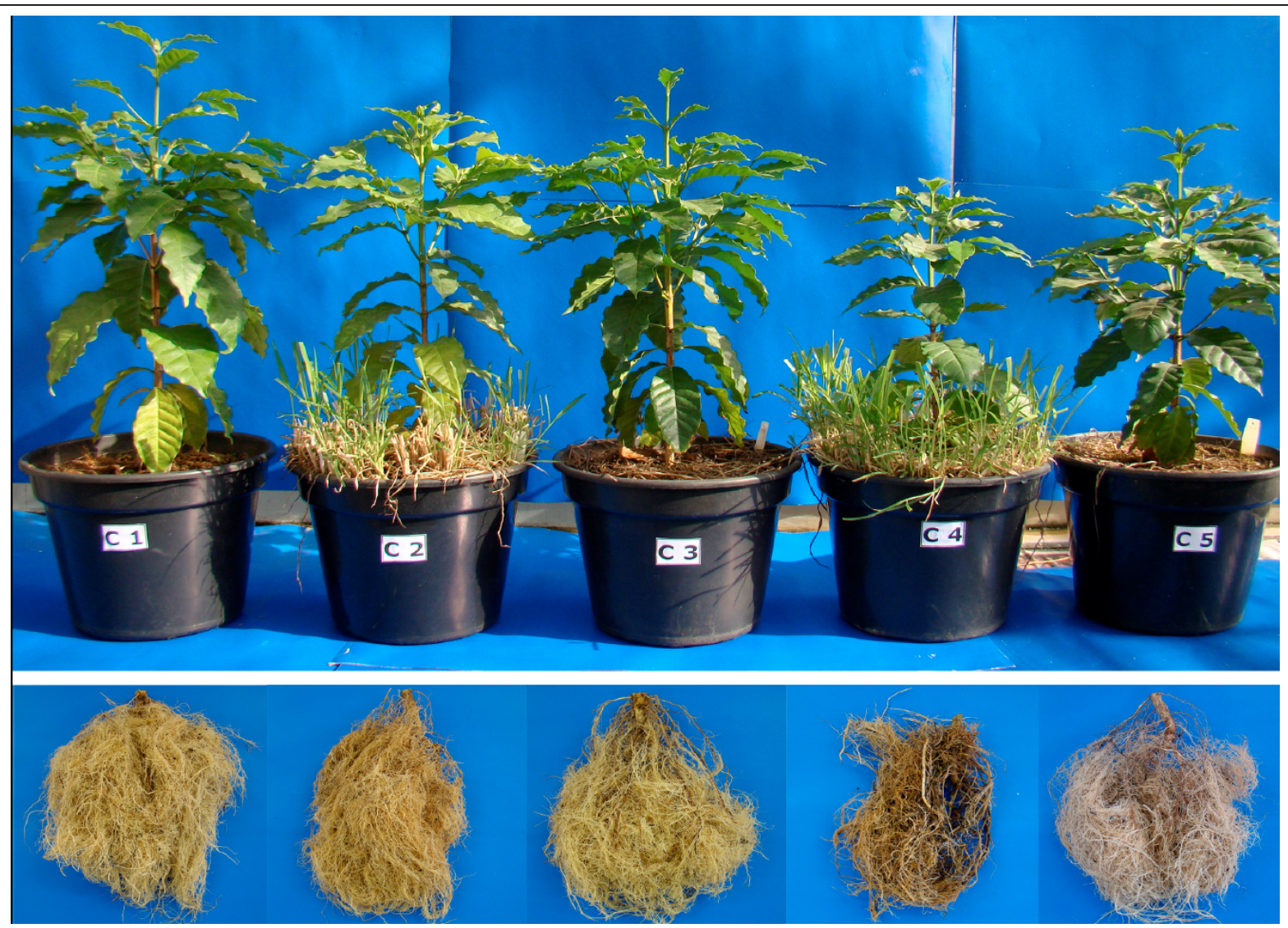

Figura 1 - Efeito do manejo de Brachiaria decumbens no desenvolvimento das raízes e parte aérea de cafeeiro, cv. 'Catuaí Vermelho', infestados por Pratylenchus brachyurus $(\mathrm{Pb})$, aos 278 dias após a inoculação das plantas. $\mathrm{C} 1$ : Café não inoculado no limpo; $\mathrm{C} 2$ : Café não inoculado consorciado com B. decumbens; C3: Café inoculado com 5000 juvenis e adultos de $\mathrm{Pb}$ por vaso (10L), no limpo; $\mathrm{C} 4$ : Café inoculado com $\mathrm{Pb}$ consorciado com $\boldsymbol{B}$. decumbens podadas semanalmente; $\mathrm{C}$ 5: Café inoculado com $\mathrm{Pb}$ consorciado com $\boldsymbol{B}$. decumbens com aplicação do herbicida glifosato.

brachyurus se reproduzem nas gramínias Brachiaria sp. e Paspalum notatum em até 90 dias após o período da safra. LORDELLO \& MELLO FILHO (1969a) sugeriram que capim pangola (Digitaria eriantha subsp. pentzii) pode ser boa hospedeira para P. brachyurus. Além dessas, as seguintes gramíneas também são listadas na literatura como hospedeiras de P. brachyurus: Melinis minutiflora, Hyparrhenia rufa, B. purpurascens, Chloris gayana, Cynodon dactylon, Panicum purpurascens, cana de açúcar e Sorghum sudanense (LORDELLO \& MELLO FILHO, 1969B; LORDELLO, 1972; CHARCHAR \& HUANG, 1991); CASTILLO \& VOLVLAS, 2007.

Os resultados obtidos no presente experimento permitem concluir que se deve evitar o plantio de cafeeiros em áreas infestadas com $\boldsymbol{P}$. brachyurus em pastagens com braquiária, bem como evitar o seu uso nas entrelinhas dos cafezais infestados com esse nematoide.

\section{AGRADECIMENTOS}

Ao Consórcio Pesquisa Café, pelo apoio financeiro concedido para execução da pesquisa. Juliana Eulálio é bolsista do Consórcio Pesquisa Café.

\section{REFERÊNCIAS}

CANTIERI, M.G. et al. Sasm-agri-sistema para análise e separação de médias em experimentos agrícolas pelos métodos Scott-knott, Tukey e Duncan. Revista Brasileira de Agrocomputação, v.1, n.2, p.18-24, 2001. Disponível em: <http://www.agrocomputacao. deinfo.uepg.br/dezembro_2001/Arquivos/RBAC_Artigo_03.pdf $>$. Acesso em: 27 ago. 2012.

CHARCHAR, J.M.; HUANG, C.S. Sobrevivência de Pratylenchus brachyurus em fragmentos de raízes de capim gordura Melinis minutiflora. Fitopatologia Brasileira, v.16, p.22-25,1991.

COOLEN, W.A.; D'HERDE, C.J. A method for the quantitative extraction of nematodes from plant tissue. Bélgica: State Nematology and Entomology Research Station, 1972. 77p.

CAStillo, P.; VOLVlas, N. Pratylenchus (Nematoda: Pratylenchindae): diagnosis, biology, pathogenicity and

Ciência Rural, v.45, n.11, nov, 2015. 
management. In: HUNT, D.J.; PERRY, R.N. Nematology monographs and prespectives. The Netherlands: Brill Academic Publishers, 2007. 6v

D'ANTONIO, A.M. et al. Levantamento de nematóides parasitas do cafeeiro que ocorrem no Sul de Minas Gerais. In: CONGRESSO BRASILEIRO DE PESQUISAS CAFEEIRAS, 8., 1980, Campos do Jordão, SP. Resumos... Campos do Jordão:Instituto Brasileiro do Café/GERCA editora ou entidade promotora 1980. p.440-443.

DIAS, G.F.S. et al. Brachiaria decumbens supresses the initial grow of Coffea arabica. Scientia Agricola, v.61, n.6, p.579-583, 2004. Disponível em: <http://www.scielo.br.sci-hub.org/scielo. php>. Acesso em: 02 out. 2012.

DROPKIN, V.H.; NELSON, P.E. The histopathology of rootknot nematode infections in soybeans. Phytopathology, v.5, n.6, p.442-447, 1960 .

GONÇALVES, W. Problemas na produção brasileira de café devido a fitonematoides. In: CONGRESSO INTERNACIONAL DE NEMATOLOGIA TROPICAL, 1995, Rio Quente, GO. Resumos... Rio Quente: SBN, 1995. p.216-223.

GONÇALVES, W. et al. Estimativas de danos ocasionados pelos nematoides do cafeeiro. In: CONGRESSO BRASILEIRO DE PESQUISAS CAFEEIRAS, 6., 1978, Ribeirão Preto, SP. Resumos... Ribeirão Preto: Instituto Brasileiro do Café/GERCA, 1978. p.182-186.

INOMOTO, M.M. et al. Effects of Pratylenchus brachyurus and P. coffeae on seedlings of Coffea arabica. Journal of Nematology, v.30, n.3, p.362-367, 1998. Disponível em: <http://www.ncbi.nlm. nih.gov/pmc/articles/PMC2620307/>. Acesso em: 08 ago. 2012.
KUBO, R.K. et al. Report of damage caused by Pratylenchus brachyurus in coffee plantation of São Paulo State. Fitopatologia Brasileira, v.25, p.338, 2000.

KUBO, R.K. et al. Ocorrência de nematoides do gênero Pratylenchus em cafezais do estado de São Paulo. Nematologia Brasileira, v.28, n.2, p.159-166.2004. Disponível em: <http:// docentes.esalq.usp.br/sbn/nbonline/ol\%20282/159-165\%20co. pdf>. Acesso em: 08 ago. 2012.

LORDELlO, L.G.E.; MELLO FILHO, A.T. O capim pangola difunde nematóides. Revista da Agricultura, v.44, n.4, p.122, 1969a.

LORDELlO, L.G.E.; MELLO FILHO, A.T. Capins gordura e jaraguá, hospedeiros novos de um nematóide migrador. O Solo, n.61, p.27-28, 1969 b.

LORDELLO, L.G.E. Nematode pests of coffee. In: WEBSTER, J.M. (Ed.). Economic nematology. London: Academic, 1972. p.268-284.

LORDELLO, L.G.E. Distribuição geográfica dos nematoides nocivos ao cafeeiro. Revista da Agricultura, v.43, n.2, p.79-81, 1968.

OLIVEIRA, C.M.G. et al. Efeito de densidades populacionais de Pratylenchus brachyurus no crescimento de plântulas de Coffea arabica cv. 'Mundo Novo' e $\boldsymbol{C}$. canephora cv. 'Apoatã'. Nematropica, v.29, n.2, p.215-221, 1999. Disponível em: <http:// journals.fcla.edu/nematropica/article/view/64251/61919>. Acesso em: 27 ago. 2012.

STRADIOTO, M.F. et al. Dinâmica populacional de Pratylenchus brachyurus em cultura do milho (Zea mays L.) infestada por plantas daninhas. Sociedade Brasileira de Nematologia, v.7, p.99-115, 1983. Disponível em: <http://docentes.esalq.usp.br/sbn/nbonline/ ol\%2007u/99-115\%20pb.pdf >. Acesso em: 27 ago. 2012. 